Article

\title{
Potential for Reuse of E-Plastics through Processing by Compression Molding
}

\author{
William Mills * and Robert A. Tatara
}

Department of Technology, College of Engineering and Engineering Technology, Northern Illinois University, Dekalb, IL 60115, USA; rtatara@niu.edu

* Correspondence: wmills11@niu.edu; Tel.: +1-815-753-5366

Academic Editors: William Bullock and Joy J. Scrogum

Received: 22 February 2016; Accepted: 10 May 2016; Published: 19 May 2016

\begin{abstract}
The amounts of e-waste, consisting of metal (e-metals) and plastic (e-plastics) streams from electronic goods, are increasing in the United States and elsewhere. The e-metals waste streams are being recycled to a reasonable degree due to the value of precious metals. E-plastic waste streams currently are not recycled or reused to a significant extent. As a result, most e-plastics are disposed of by landfilling or thermal treatment, or sent overseas for alleged recycling or reuse, any of which could result in unsafe worker exposure and release into the environment. Two of the major barriers to e-plastics' reuse or recycling are the mixed plastic content and the presence in the e-plastics of flame retardants (FR), of which two classes in particular, the brominated flame retardants (BFR) and organo-phosphorus flame retardants (OPFR), have associated health concerns. The major goal of this project is to investigate the possibility of direct reuse of e-plastics in compression molding. Preliminary data generated have identified a molding procedure that yields remanufactured e-plastics having a tensile strength of 29.3 MPa. This moderate strength level is suspected to be due to inclusions of plastic bits that did not melt and internal voids from out-gassing. Handheld X-ray fluorescence (XRF) was utilized to characterize elemental components in the e-plastics tested for compression molding. Several high "hits" for Br were found that could not be predicted visually. The preliminary XRF data for BFR and OPFR in this work are helpful for environmental and occupational hazard assessments of compression molding activities. Additionally, methods are suggested to characterize the metals, BFR, and OPFR content of the e-plastics using several different additional laboratory analytical techniques to determine the suitability for cost-effective and easy-to-use technologies.
\end{abstract}

Keywords: Waste Electrical and Electronic Equipment (WEEE); e-plastics; compression molding; recycling; flame retardants; GC-MS; XRF

\section{Introduction}

\subsection{E-Waste}

Waste material from electronics is referred to by a variety of terms including e-waste (or e-wastes) [1] and waste electrical and electronic equipment (WEEE) [2]. In 2012, the United States (US) generated at least 3.4 million tons of e-waste [3]. The amount of e-waste being generated is steadily increasing, both in the US and worldwide [4]. The e-waste stream consists of electronics items, such as computers, television and computer monitors, cell phones, printers/fax machines/scanners/ multifunctional devices, audio video devices (stereos, VCR, DVD players, etc.), as well as electrical items, such as household appliances [5]. The US Environmental Protection Agency (USEPA) has estimated that only approximately $25 \%$ of domestic e-waste is currently being recycled or reused [6]. At the same time, an increasing number of states are restricting or banning the landfilling of e-waste. For example, in Illinois, many e-wastes have been banned from landfills since January 2012 [7]. 
The e-waste stream can generally be divided into two substreams:

(1) metals-containing wastes (e-metals), and

(2) plastics (e-plastics).

E-metals contain valuable gold, silver, platinum, palladium, rare earths, etc., for which cost-effective processes have been developed for recovery and/or recycling [8]. E-metal recovery is believed to make up most of the $25 \%$ of US e-waste that is recycled. However, too much e-plastic is still ending its useful life in a landfill or dumpsite due to a lack of materials' management. E-plastics is an abundant resource for high quality engineering resin as, on a volume basis, it is the largest component of e-wastes [9].

\subsection{E-Plastics}

E-plastics represent a larger fraction of the e-waste stream than e-metals, and there are significantly fewer options for their recycling or reuse. The general challenges associated with plastics recycling have been reviewed $[10,11]$. In addition to these general plastic recycling challenges, two of the major barriers to reuse of e-plastics are (1) the mixed nature of the plastics stream and (2) the possible flame retardant (FR) content of the e-plastics. Major types of polymers (plastics) in the e-plastics stream include acrylonitrile butadiene styrene (ABS), polyethylene (PE), polypropylene (PP), polycarbonate (PC), polyvinylchloride (PVC), high impact polystyrene (HIPS), or blends of these thermoplastics $[9,12,13]$. However, thermosets (epoxy and phenol formaldehyde, for instance) and elastomers are present in small quantities. Potentially useful e-plastics are all the plastic components of electrical devices except for circuit boards, which contain electronic chips, wiring, metals, and fiberglass reinforcement. Separating out the plastic components of a circuit board is cost-prohibitive. FRs have been used widely in the e-plastics for consumer electronics. FRs found in e-plastics are generally brominated flame retardants (BFR) or organophosphorus flame retardants (OPFR) [11]. The BFRs, especially polybrominated diphenyl ethers (PBDE), have received a great deal of attention due to their widespread occurrence in the environment, including the Great Lakes [12-16], and in electronic recycling facilities, as there are concerns about their toxicity and occupational exposures [17-19]. In recent years, many of the PBDEs have been phased out and replaced by other BFRs or OPFRs; however, many of the newer FRs have similar physical/chemical properties, and in many cases toxicity is still an issue. It is not clear whether the replacements BFR represent a better solution [20].

Most e-plastics options require separation of the e-plastics into their different polymers to be used by conventional processing options such as injection molding, extruding, and blowmolding. This separation/sorting can be a costly and formidable task. Sorting of e-plastics is often performed manually, but this is cost-prohibitive in the US. The use of automated sorting has been investigated, but requires significant investment in equipment [14].

As a result of these issues, most e-plastics are currently disposed of by landfilling or incineration/ pyrolysis, or shipped overseas for alleged recovery $[8,15]$. The thermal treatment of e-plastics is of concern because of the potential for the production of emission products, such as brominated dioxins [4,16-19]. The shipment of e-wastes from developed countries to lesser-developed ones has resulted in significant waste disposal and exposure concerns [20-24].

Environmental and Health and Safety (EHS) concerns associated with e-waste recycling exist $[4,20,21,23,25-34]$. However, informational gaps are present. For example, recent NIOSH Health Hazard Evaluations (HHEs) did not address FRs in workplace air sampling or biological monitoring $[25,26]$. There is little information on the metal content remaining in e-plastics after separation of the e-metals.

\subsection{Analysis of E-Plastics}

As noted above, two of the biggest barriers for the recycling of e-plastics are the wide variety of possible polymers in the e-plastics and the potential for FR in these materials. For example, 
in the European Union (EU), there is a restriction of $0.1 \%$ for BFR concentration in WEEE $[13,35,36]$. Concentrations of BFR above this value would make it difficult for the e-plastics to be reused or recycled.

The analysis (for sorting purposes) of the different types of polymers can be performed by a wide variety of techniques, of varying complexity and cost. Some examples of techniques that have been used include Fourier transform infrared spectroscopy (FT-IR), non-dispersive infrared spectroscopy (NDIR), Raman spectroscopy, and thermal methods such as thermogravimetric analysis (TGA) or differential scanning calorimetry (DSC) [37]. Real-time sorting of plastics by type of polymer is being done for regular plastics [14]: however, the equipment often requires a significant upfront investment.

Analysis of BFRs and OPFRs in e-plastics has typically been performed using analytical techniques that involve physical sample preparation by grinding/chopping etc., solvent extraction and cleanup, and extract analysis with gas chromatography-mass spectrometry (GC-MS) [38-42] or liquid chromatography-mass spectrometry (LC-MS) [43-47]. More recently, the use of other methods including X-ray fluorescence (XRF) [48-50], Raman spectroscopy [50], Ion beam analysis (IBA) [51,52], and thermal analytical methods such as thermal desorption GC-MS have been proposed for FR analysis [39,53-55]. XRF and IBA methods analyze for elemental composition, using the $\mathrm{Br}, \mathrm{Cl}$, and $\mathrm{P}$ levels as a surrogate for the FR itself, i.e., elevated levels of $\mathrm{Br}, \mathrm{Cl}$, and/or $\mathrm{P}$ would indicate the presence of the FR.

Metals analysis is typically performed using atomic absorption spectroscopy (AAS), inductively coupled plasma and optical emission spectroscopy (ICP-OES), or mass spectrometry (ICP-MS).

The types of analytical methods outlined above are typically associated with expensive instrumentation that require support facilities, and staff with extensive education/training in order for the analyses to be performed reliably. This can result in analytical costs of hundreds to thousands of dollars per sample. This analytical cost often negatively affects the number of samples that can be analyzed in studies. In many cases, the analytical method is excessive for the question being asked;for example, does that e-plastic contain more than $0.1 \%$ (1000 ppm) BFR? There are clear opportunities for the introduction of lower-cost and more portable analytical methods for FR in e-plastics that would allow for a faster and less expensive "screening"-type analysis of e-plastics.

\subsection{E-Plastics Processing}

One potential outlet for e-plastics reuse is compression molding. Currently, e-plastics are available in chopped/ground/shredded granular form with great variance in particle size, color, and polymer composition. Figure 1 is representative of different batches of e-plastic resin generated from an e-waste recycling facility in Illinois. Note the presence of colors and the large, irregular objects that did not completely reduce to granules. Compression molding was one of the first industrial methods for plastics, with equipment dating back 100 years [56]. The basic process consists of heating a thermoset resin, under severe pressure, within a closed mold cavity until the resin cures through a chemical reaction where smaller molecules link forming high-molecular-weight polymeric chains. Under the pressure, the resin also liquefies and flows, taking the shape of the mold cavity, and then hardens into the desired part or product. Once sufficiently cooled and strong, the part is removed from the mold and the cycle is complete although the curing reaction continues while cooling to ambient (room) conditions. Thermoplastics are already fully reacted, thus are shaped by first softening the resin through preheating, within the mold or in an external oven, then using pressure to form the part. Instead of a chemical reaction, a simple phase change takes place as the material again hardens upon cooling. Although compression molding is mostly associated with thermosetting resins, PP is a thermoplastic that is easily and routinely molded by this process. 


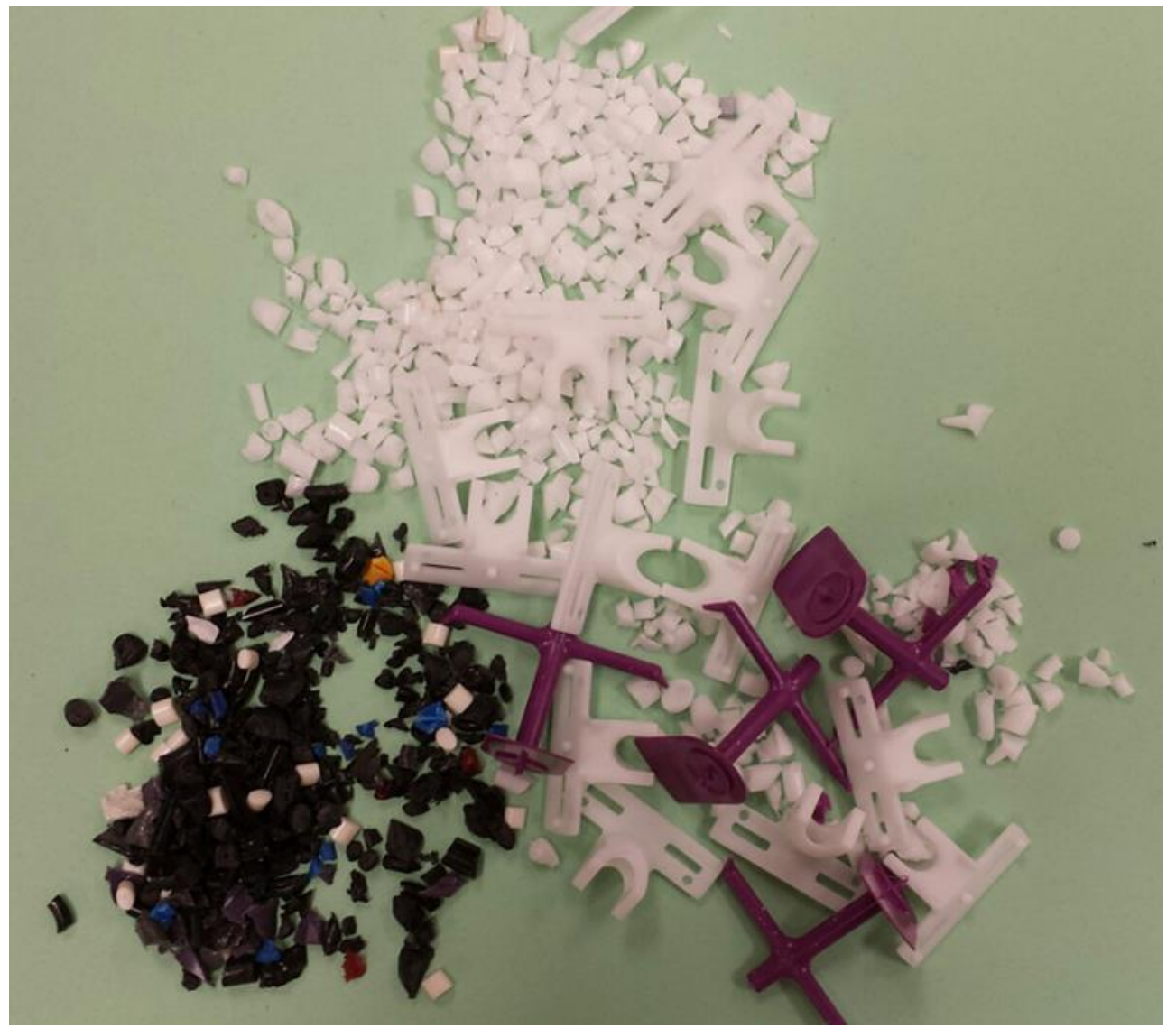

Figure 1. Typical selection of chopped/ground/shredded e-plastic resin.

This process is suitable for many industrial, commercial, and consumer products from very small appliance knobs to large automobile body panels [56-60]. General product areas are packaging, lighting and electrical, transportation, and appliances. Specific items are electrical wall switch plates and receptacles, circuit breakers, bottle caps, buttons, containers, covers, protective helmets, pump components, gears, brake parts, frames, pulleys, vehicle panels, dishware, and appliance housings, bases, handles, and knobs. Possibilities range from simple geometries to complex three-dimensional shapes, and only very large, longish (pipes, ducts, tubes) or hollow parts are prohibited [56,58].

Compression molding is much less dependent on having a pure, or even known, feed stream composition [56]. Likewise, the process is relatively insensitive to changes in additive (flame retardants being an additive) concentrations. This is due to the fact that the process is fundamentally a heated vise, which applies a closing force upon the two mold halves. The molds are easily separated from the compression-molding machine should there be problems with the molding resin. In other plastic processing techniques, the resin is extruded through the equipment into a mold or die, and material problems may produce significant control problems or even equipment damage. E-plastics are primarily mixed thermoplastics of varying melting points. There can also be thermosets and elastomers present; these cannot be remelted. Therefore, processing conditions such as temperature and pressure cannot be narrowly prescribed. Without sorting, this eliminates the use of e-plastics streams from most plastics processing methods. The simplistic operation and tooling of compression molding makes this process optimal for molding e-plastics. In addition, compression molding equipment is generally less expensive than other plastics processing equipment, so that this processing option is useful for e-plastics' reuse in less developed countries. 
There have been experimental studies attempting to mold e-plastics. Lakshmi and Nagan [61] have crushed and ground e-plastics for use as replacement material for a portion of the coarse aggregate in cemented concrete mixtures. Up to $28 \%$ of the aggregate was substituted. Strength, durability, and chemical resistance tests demonstrated that e-plastics is a feasible utilization of an otherwise waste material.

In the case of ABS, Arnold, Alston, and Holder [62] compounded granules at $210{ }^{\circ} \mathrm{C}$ for four minutes and compression molded them at $210{ }^{\circ} \mathrm{C}$ into flat bars for flexural strength testing. Data indicated mostly good strength (above $80 \%$ of virgin ABS-molded bars), but some batches exhibited unexpectedly low strength. As much as $50 \%$ reduced flex strength was found and attributed to incomplete blending of the resin into a truly homogeneous material and/or voids in the material. The voids were caused by polymer degradation products, primarily from the styrene. Results implied that better mixing prior to molding, along with elimination of the trapped degradation gases, allows for reuse of the ABS.

Balart et al. [63] blended ABS and PC e-plastics in an extruder, at $220^{\circ} \mathrm{C}$, up to $60 \%$, by weight, PC; the blends were injection molded into samples and tensile and impact testing was performed. Tensile strength of blends was slightly lower than that of pure ABS but far below that of pure PC even at $60 \%$ PC. Overall, $10 \%-20 \%$ PC represents a reasonable blend with only a small decrease from the $100 \%$ ABS level. Some of the decrease was attributed to heat degradation of the butadiene rubber in the ABS. Improved mixing of the two resins into a more homogeneous phase is thought to result in better performance. In another study, ABS and PC e-plastics were washed, then vacuum-oven dried for four hours at $80^{\circ} \mathrm{C}$ and $120^{\circ} \mathrm{C}$, respectively, for eventual strength tests [64]. Test coupons were injection molded at 1.0 MPa. Tensile strength of ABS was $16 \%$ lower compared with virgin ABS, probably due to degradation of its butadiene phase. Stiffness, as determined through the tensile modulus, decreased about the same level. Flexibility, measured via extension to break, was only half that of virgin resin, and impact strength was lowered by about $35 \%$. Interestingly, tensile strength and modulus of the PC matched its virgin resin. However, its extension to break and impact strength decreased by $25 \%$ and $45 \%$, respectively. Then, ABS/PC mixtures were produced using a twin-screw microcompounder at $260^{\circ} \mathrm{C}$ and $40 \mathrm{rpm}$. However, the blends were not as successful, and only further depressed extension as well as tensile and impact strengths from the already lower e-plastics-ABS levels; but tensile modulus values were very near virgin ABS. Some property improvement was found after the blending of coupling agent additives, such as epoxy or nanoclays, into the ABS/PC mixtures, but it should be pointed out that any additives or extra processing contributes to product expense and negates the primary benefit of utilizing e-plastics: its low cost.

\subsection{Project Background}

The authors received funding from an internal competitive grant program (Research and Artistry) at Northern Illinois University (NIU). The primary objectives for the project were:

1. Investigate the feasibility of using e-plastics for compression molding instead of disposal;

2. Obtain information on the FR and metals content from samples of e-plastics used for compression molding testing;

3. Identify and if possible test, lower cost, simpler, and more portable analytical methods for FR concentration in e-plastics

This paper provides a summary of the preliminary results from this project. Figure 2 contains a schematic of the work. 


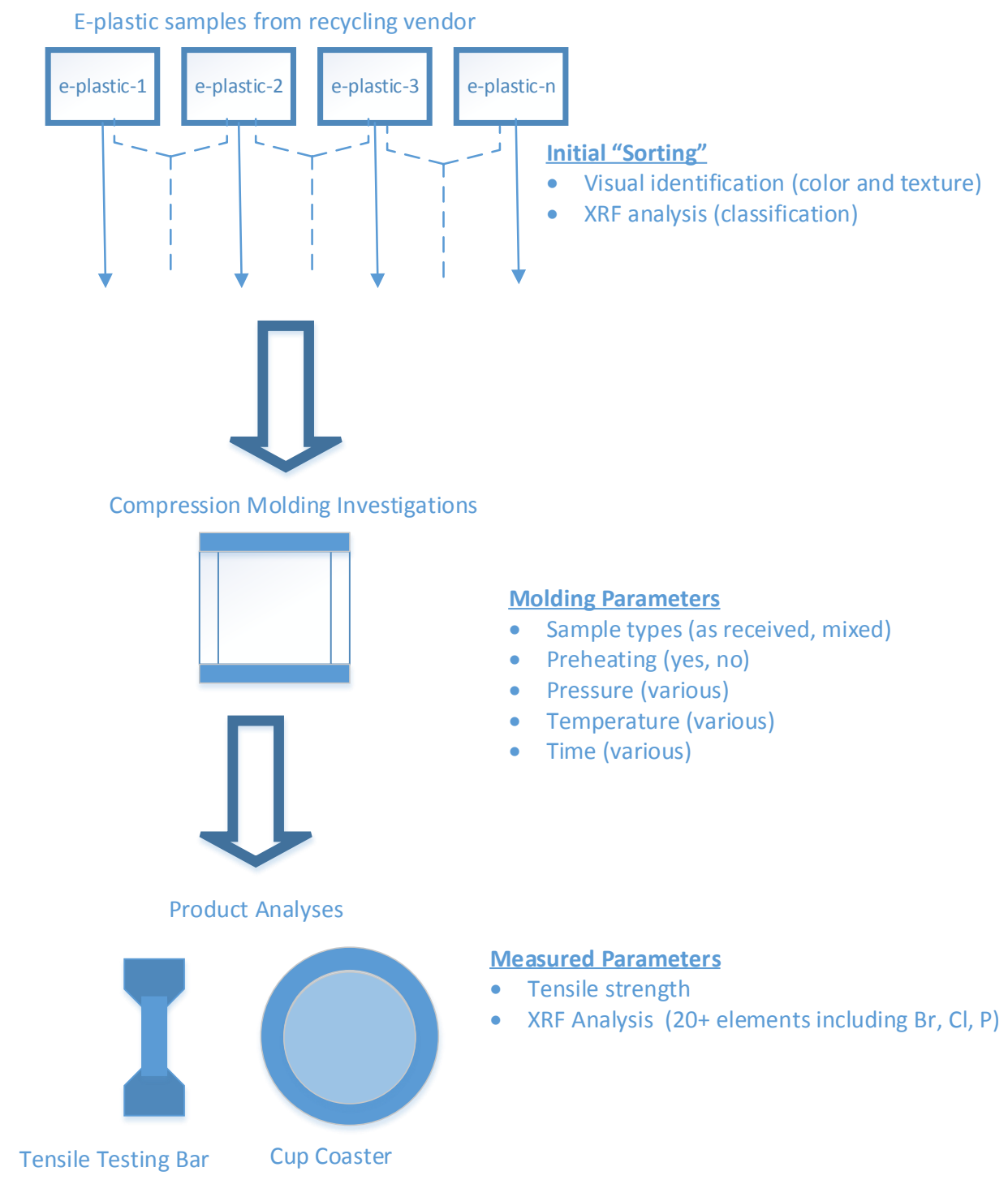

Figure 2. Schematic representation of work covered in this paper.

\section{Results}

\subsection{Compression Molding of Some Sample E-Plastics}

There are currently no established guidelines or data for the processing of e-plastics. Therefore, to increase its value by promoting e-plastics to a usable engineering material, one goal of this study was to assess suitable compression molding conditions. Variables of concern that have been identified are molding temperature, molding pressure, and molding time. Other processing considerations are resin preheating and venting of the mold. Because the generation of e-waste is projected to increase significantly in the future, another objective of this study is to quantitatively characterize some primary mechanical properties; data gathered include mechanical strength.

Figure 3 shows an example of a compression-molding form using the e-plastic shown in Figure 1. The heterogeneous nature of the e-plastic can clearly be seen. To better understand the processability of this material, 15 samples (in groups of three using a three-cavity aluminum mold) were molded and tensile strength tested, yielding a mean tensile strength of $29.3 \pm 10.0 \mathrm{MPa}$. Figure 4 shows this averaged data along with several other selected plastics. The strength is reasonable, compared to other common, commercial plastics, and proves that such heterogeneous e-plastic can be molded without special or extra processing. Along with the measured mean, there exists a large uncertainty $( \pm 10.0 \mathrm{MPa})$ 
in the trials. However, it must be pointed out that the 15 samples originated from six different batches of unknown product of unknown polymeric composition. No attempt was made to systematically sort the e-plastic or vary molding parameters in a design-of-experiments (DOE) fashion. At this time, the goal was to demonstrate that with such a variable and heterogeneous resin could be molded at all. Thus, large uncertainty in the measured strengths was expected.

Although the resin composition in the testing was not known, it is likely that ABS, PS, and/or PC were present. Figure 4 indicates that the material's strength is significantly less than that of these standard plastics or their copolymers and blends. Inspection of individual tensile bars after testing uncovered inclusions of plastic bits that did not soften or melt to fuse with surrounding material along with many internal voids. The inclusions and voids certainly diminish strength. Arnold, Alston, and Holder [38] experienced similar quality problems after processing ABS e-plastic through an extruder prior to compression molding test specimens. Their voids were mostly attributed to styrene degradation gassing and not due to any water evaporation since their pre-dried resin displayed the same behavior.

In future studies, variations in the preheating technique could reduce the level of unmelted bits. Also, a redesign of the mold to facilitate gas and volatiles venting should minimize voidage and similarly improve moldability and strength.

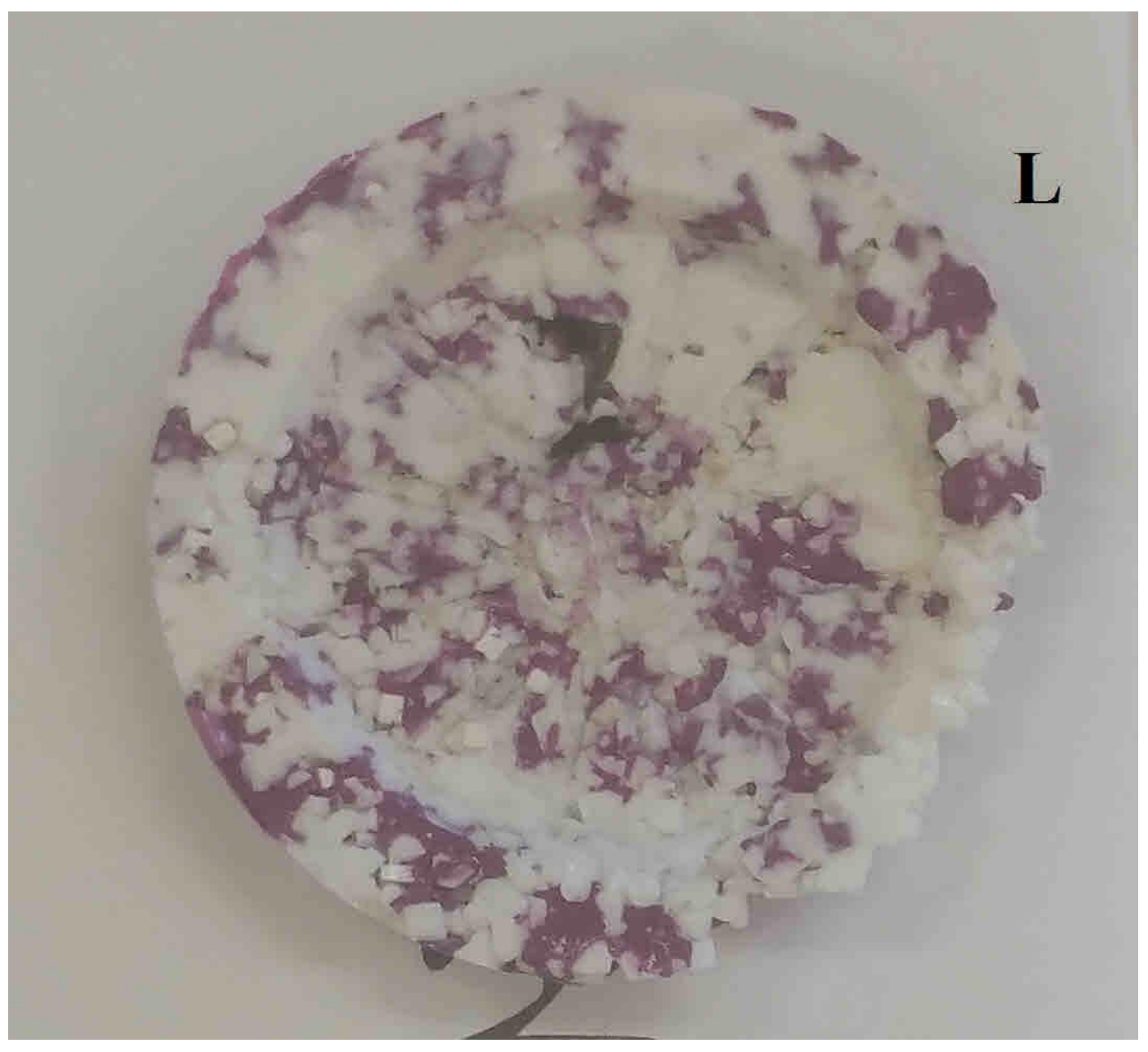

Figure 3. Example compression molding “coaster," Letter ID = L (see Table 1). 


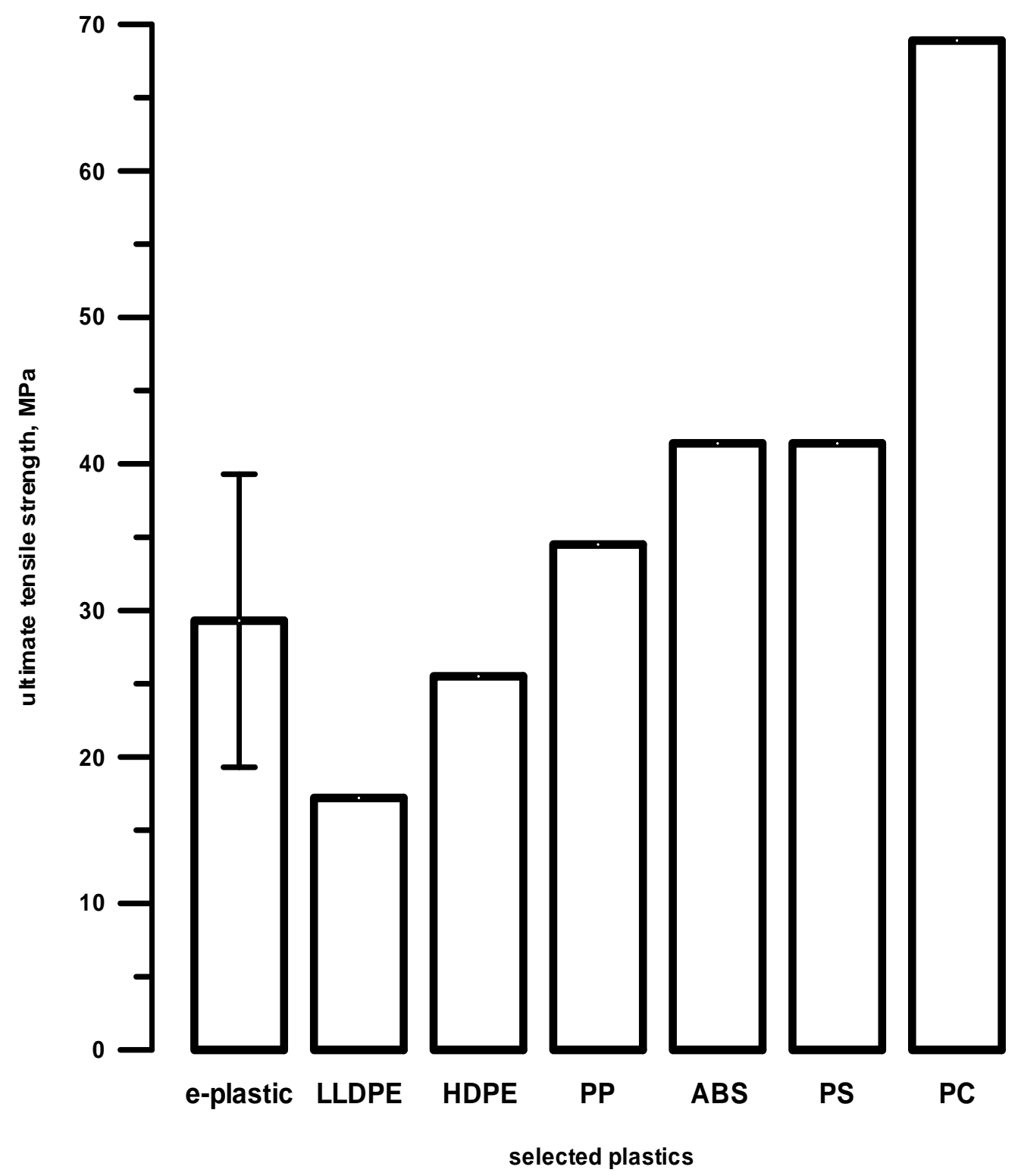

Figure 4. Comparative tensile strength of e-plastics from this study. Reference values for LLDPE, HDPE, PP, ABS, PS,g and PC are from Strong [65].

\subsection{Preliminary Screening Analysis}

Another of the goals for this project was to obtain information on the metals and FR content of e-plastics that were used for the compression molding demonstrations discussed in 2.1. We chose to utilize hand-held XRF as a screening analytical technique, since one of us (Dr. William Mills) has been using this technique since 1992 for EHS issues [66] and instrument availability. The XRF technique is well-suited to the types of materials encountered in the e-plastics. It provides elemental analysis, including for certain instruments, bromine, chlorine, and phosphorus (which can be used as surrogates for the FR). Hand-held XRF offers additional advantages over the typical laboratory XRF analysis in terms of the portability and ease of use, without necessarily any significant reduction in accuracy/precision.

Figures 5 and 6 show some of the samples that were analyzed by hand-held XRF. A total of 27 elements were analyzed using the XRF. Table 1 contains the data generated for a subset of $\mathrm{Br}, \mathrm{Cl}$, $\mathrm{P}, \mathrm{Hg}, \mathrm{Pb}, \mathrm{Cr}, \mathrm{Co}, \mathrm{Ni}, \mathrm{Cu}$, which were considered of most interest for this project. Table 2 provides 
a summary of the minimum and maximum values for each of these elements. The Table S1 in the supplementary contains the full analysis results for the 27 elements. Additional analytical information is provided in the Materials and Methods section.

\section{Discussion}

Preliminary molding and testing has shown that e-plastics can be processed with reasonable mechanical strength. Figure 4 compares the measured tensile strength of the e-plastics from this study with some conventional resins [65]. The e-plastics have significantly better strength than linear low-density polyethylene (LLDPE) and high-density polyethylene (HDPE). However, expectedly, it is weaker than PP, polystyrene (PS), ABS, and PC. Furthermore, it is believed that reducing the voids from gassing during molding is achievable in the future and would recover the e-plastics' strength to near $40 \mathrm{MPa}$, thus elevating its strength to that of engineering plastics such as ABS and PC. This opens e-plastics to use in many compression-molded products although medical- and food-related ones would be excluded due to the variability in FR content of the e-plastics stream. Products routinely exposed to high temperatures also would not be suitable since the vast majority of e-plastics is thermoplastic with the potential to melt.

Ideally, consumer products with the requirements of moderate strength and durability would benefit from e-plastics. Some projected areas are outdoor stakes, signs, frames, planting containers, fencing, and furniture components. All of these are easily compression molded. From a processing standpoint, even e-plastics with FRs can potentially find reuse. However, the marketplace will most likely find that e-plastics with no or low levels of FRs are acceptable, and all other e-plastics that are either difficult to sort or contain FRs would be landfilled or incinerated for energy production. Additionally, even if the ability to screen and separate e-plastics into batches of homogeneous resins is improved, further research must depend on experimental data as prediction of properties from the composition or content of e-plastics a priori is speculative.

There are several things that stand out for the XRF data in the Tables 1 and 2 data. First off, while there is a clear amount of visible heterogeneity in the e-plastics starting material (Figures 1, 3, 5 and 6), there was no immediate or clear way of determining or predicting which e-plastics starting material would be elevated in any of the elemental parameters. There is a large spread on the bromine values with a maximum of approximately 500,000 ppm for (letter ID = D.) Three measurements were made on this item (letter ID, D), two of them were very close to each other, while another was approximately $1 / 5$ of the other two values, but still over $10 \%$ by weight (i.e., 100,000 ppm). Based on discussions with the analytical instrument manufacturer (Olympus), this amount of variability at this concentration is not unheard of. All of these results were $>100,000 \mathrm{ppm} \mathrm{Br}$, which is much higher than the EU $0.1 \%$ total BFR WEEE restriction. For the e-plastics starting material, the black plastic (letter ID, G) had the highest bromine level. None of the e-plastics starting material Br values could account for the high $\mathrm{Br}$ values observed in the test bar. In contrast, none of the e-plastics samples contained significant amounts of chlorine or phosphorus (all P measurements were below the limit of detection). The white paper was analyzed without and then with a black marker in order to determine if the black marker had any elevated concentrations. A review of the data in Table 1 does indicate that the paper and black marker were elevated in $\mathrm{Cl}$ but not in other elements. In terms of metals, the values seen in the samples were generally quite low, although one e-plastics starting material (letter ID, G) had 259 ppm of lead, one to two orders of magnitude higher than that seen in the rest of the e-plastics.

These results indicate that the separation process being used for e-metals seems to be doing a good job of preventing them showing up in e-plastics. The results also serve to illustrate the heterogeneity issue of e-plastics with regards to FR content, as well as the lack of visual indicators of the FR content and how implementation of a robust screening analysis could help prevent entry into the recycling stream of e-plastics containing FR. 


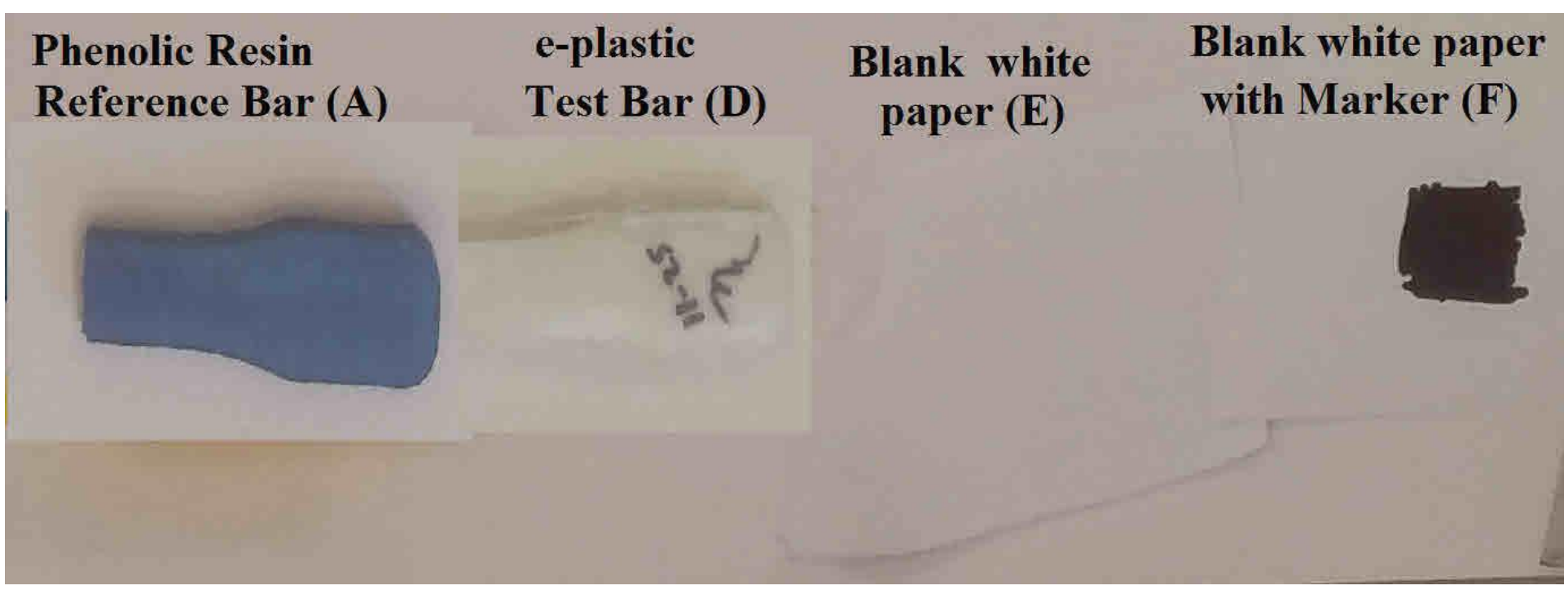

Figure 5. E-plastics samples (A-F) analyzed by hand-held XRF (see Table 1 and Table S1).

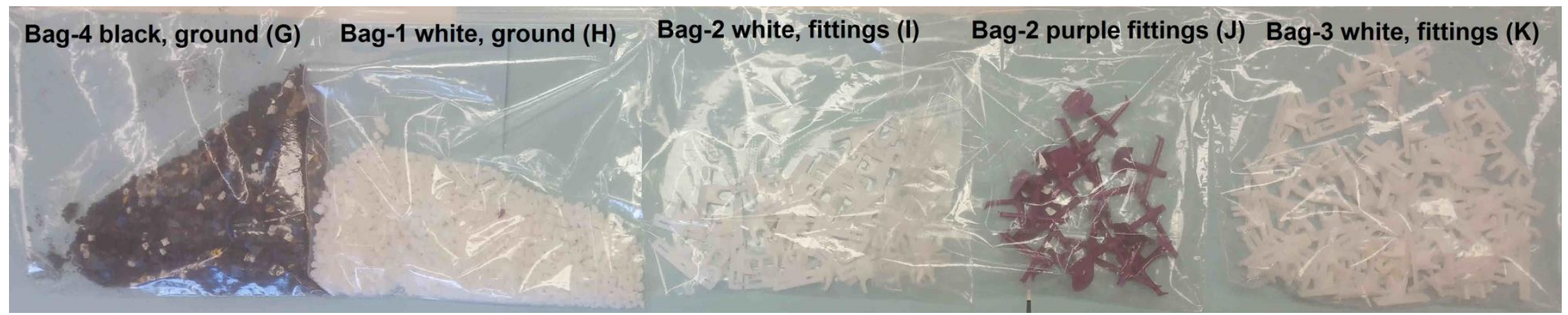

Figure 6. E-plastics samples (G-K) analyzed by hand-held XRF (see Table 1 and Table S1). 
Table 1. Hand-held XRF data for analysis of selected elements in e-plastics.

\begin{tabular}{|c|c|c|c|c|c|c|c|c|c|c|c|}
\hline Material Source & $\begin{array}{c}\text { Letter ID } \\
\text { (Figures } 5 \text { and 6) }\end{array}$ & $\begin{array}{c}\text { Elapsed } \\
\text { Time Total }\end{array}$ & Br & $\mathrm{Cl}$ & $\mathbf{P}$ & $\mathrm{Hg}$ & $\mathrm{Pb}$ & $\mathrm{Cr}$ & Co & $\mathbf{N i}$ & $\mathrm{Cu}$ \\
\hline Phenolic Resin—Reference Bar & A & 44.13 & & 399 & $<\mathrm{LOD}^{1}$ & $<\mathrm{LOD}$ & 9 & $<$ LOD & $<\mathrm{LOD}$ & $<\mathrm{LOD}$ & 961 \\
\hline Phenolic Resin—Reference Bar & A & 44.12 & & 420 & $<\mathrm{LOD}$ & $<$ LOD & 6 & 11 & $<\mathrm{LOD}$ & $<\mathrm{LOD}$ & 983 \\
\hline e-Plastic Test Bar & B (no photo) & 44.68 & & 208 & $<\mathrm{LOD}$ & $<$ LOD & 9 & 11 & $<$ LOD & $<$ LOD & $<\mathrm{LOD}$ \\
\hline Phenolic Resin (powder) & $C$ (no photo) & 44.13 & 43 & 69 & $<\mathrm{LOD}$ & $<\mathrm{LOD}$ & 36 & $<\mathrm{LOD}$ & $<\mathrm{LOD}$ & $<\mathrm{LOD}$ & 2600 \\
\hline e-Plastic-Test Bar & $\mathrm{D}$ & 43.57 & 547,244 & 43 & $<$ LOD & $<$ LOD & $<$ LOD & $<$ LOD & $<\mathrm{LOD}$ & $<\mathrm{LOD}$ & 170 \\
\hline e-Plastic_-Test Bar & $\mathrm{D}$ & 43.65 & 545,085 & 36 & $<$ LOD & $<$ LOD & $<$ LOD & $<$ LOD & $<\mathrm{LOD}$ & $<\mathrm{LOD}$ & 143 \\
\hline Blank white paper & $\mathrm{E}$ & 45.06 & $<\mathrm{LOD}$ & 1705 & $<\mathrm{LOD}$ & $<$ LOD & $<\mathrm{LOD}$ & 382 & $<\mathrm{LOD}$ & $<\mathrm{LOD}$ & 324 \\
\hline Blank white paper with Black Marker & $\mathrm{F}$ & 44.97 & $<\mathrm{LOD}$ & 4292 & $<$ LOD & $<$ LOD & $<\mathrm{LOD}$ & 575 & 2641 & $<\mathrm{LOD}$ & $<\mathrm{LOD}$ \\
\hline Black e-plastic, ground up (Bag-4) & G & 43.56 & 77,904 & 532 & $<\mathrm{LOD}$ & $<\mathrm{LOD}$ & 259 & 134 & $<$ LOD & $<\mathrm{LOD}$ & 484 \\
\hline White e-Plastic, ground up (Bag-1) & $\mathrm{H}$ & 43.71 & 2560 & 11 & $<\mathrm{LOD}$ & $<\mathrm{LOD}$ & $<\mathrm{LOD}$ & $<\mathrm{LOD}$ & $<\mathrm{LOD}$ & $<\mathrm{LOD}$ & $<\mathrm{LOD}$ \\
\hline White e-Plastic, fittings (Bag-2) & $\mathrm{I}$ & 44.56 & 44 & 25 & $<\mathrm{LOD}$ & $<\mathrm{LOD}$ & 37 & 65 & $<\mathrm{LOD}$ & $<\mathrm{LOD}$ & $<\mathrm{LOD}$ \\
\hline Purple e-Plastic, fittings (Bag-3) & $\mathrm{J}$ & 44.42 & 50 & 63 & $<\mathrm{LOD}$ & $<\mathrm{LOD}$ & 30 & $<\mathrm{LOD}$ & $<\mathrm{LOD}$ & $<\mathrm{LOD}$ & $<\mathrm{LOD}$ \\
\hline White e-Plastic, fittings (Bag-3) & K & 44.18 & 44 & 15 & $<\mathrm{LOD}$ & $<\mathrm{LOD}$ & $<\mathrm{LOD}$ & $<\mathrm{LOD}$ & $<\mathrm{LOD}$ & $<$ LOD & $<\mathrm{LOD}$ \\
\hline Purple/White e-Plastic, compression mold test & $\mathrm{L}$ & 43.77 & 526 & 21 & $<\mathrm{LOD}$ & $<\mathrm{LOD}$ & $<\mathrm{LOD}$ & $<\mathrm{LOD}$ & $<\mathrm{LOD}$ & $<\mathrm{LOD}$ & $<\mathrm{LOD}$ \\
\hline Purple/White e-Plastic, Test Bar & M (no photo) & 44.38 & 77 & 19 & $<\mathrm{LOD}$ & $<\mathrm{LOD}$ & 30 & $<\mathrm{LOD}$ & $<\mathrm{LOD}$ & $<\mathrm{LOD}$ & $<$ LOD \\
\hline White e-Plastic Test Bar (repeat) & $\mathrm{D}$ & 44.28 & 118,564 & 34 & $<\mathrm{LOD}$ & $<\mathrm{LOD}$ & $<\mathrm{LOD}$ & $<\mathrm{LOD}$ & $<\mathrm{LOD}$ & $<\mathrm{LOD}$ & 28 \\
\hline
\end{tabular}

${ }^{1} \mathrm{LOD}=$ limit of detection.

Table 2. Minimum/maximum summary for data in Table 1.

\begin{tabular}{cccccccccc}
\hline & $\mathbf{B r}$ & $\mathbf{C l}$ & $\mathbf{P}$ & $\mathbf{H g}$ & $\mathbf{P b}$ & $\mathbf{C r}$ & $\mathbf{C o}$ & $\mathbf{N i}$ & $\mathbf{C u}$ \\
\hline $\min$ & 43 & 11 & LOD & LOD & 5.6 & 9.7 & 2641 & LOD & 28 \\
\hline $\max$ & 547,244 & 4292 & LOD & LOD & 259 & 575 & 2641 & LOD & 2600 \\
\hline
\end{tabular}




\section{Materials and Methods}

\subsection{Compression Molding}

To examine the possibility of compression molding, several small, typical batches of e-plastics were obtained from a northern Illinois recycler (See Figures 5 and 6 and Table 1). The white e-plastic in Bags 1 and 2 are believed to have been produced from grinding of the "fittings" in Bags 2 and 3. Their exact compositions were unknown but ABS and PC are thought to be the dominant plastics. By varying molding temperature and pressure with the inclusion of preheat, visually reasonable test bars were produced with this material. The optimal conditions included softening the charge with $30 \mathrm{~min}$ of preheat at $204^{\circ} \mathrm{C}$, followed by a molding pressure of $17.2 \mathrm{MPa}$ at $204{ }^{\circ} \mathrm{C}$ for $4 \mathrm{~min}$. A 7075-T651 aluminum three-cavity mold was utilized. It has a mass of $5.8 \mathrm{~kg}$ and, when closed, measures $191 \mathrm{~mm}$ in length, $152 \mathrm{~mm}$ in width, and $70 \mathrm{~mm}$ in height. The molder was a commercial, $267 \mathrm{kN}$ electric/hydraulic unit (Model AutoFour/30-D, Carver Inc., Wabash, IN, USA [67]) with $305 \mathrm{~mm} \times 305 \mathrm{~mm}$ heated platforms. The tensile bars are the typical ASTM [68] "dog-bone" shaped-165.1 mm long, with width and thickness in the narrow (i.e., break) region measuring $12.7 \mathrm{~mm}$ and $3.2 \mathrm{~mm}$, respectively. Consistent samples were produced, as demonstrated by their uniform thickness, even when molding up to three at once. Using a commercial, 24.5-kN tensile tester (Model EZ 50, Lloyd Instruments Ltd., Hampshire, UK [69]) according to ASTM D638-14 [68] each tensile bar was pulled until complete break with this corresponding to the ultimate, and maximum, tensile strength (UTS) of the material. Tensile pulling speed was $5 \mathrm{~mm} / \mathrm{min}$ for all samples.

\subsection{Hand-Held XRF Analysis}

An Olympus Delta Professional hand-held XRF [70] (Olympus, Newton, MA, USA) was used for XRF analysis. This instrument was calibrated by the service center prior to use [71]. Samples were analyzed on a "as is" basis. The soil mode was utilized for all analyses. For each sample three readings were obtained of approximately 15 seconds each (i.e., total analysis time of approximately 45 seconds for each result) and the average value was calculated, along with a standard deviation. Tables 1 and 2 contain selected XRF data. The complete data set produced is contained in Table S1 of the supplementary file.

\section{Future Research and Conclusions}

The preliminary data produced for the compression molding is promising and adds to the available data set for e-plastics. However, the two biggest obstacles to the reuse/recycling of e-plastics remain the heterogeneity in the types of polymers and the heterogeneity in terms of the flame retardant concentrations. Future work is being undertaken at NIU that will address both of these issues.

For the FR analysis in e-plastics, the hand-held XRF appears to be very promising, considering cost, ease-of-use, portability, performance, and sample throughput. Additional work is planned with hand-held XRF using both the Olympus as well as those from other instrument manufacturers. This work will include the evaluation of options such as a built-in camera, different data processing, and source configurations. The XRF, while an excellent screening tool, does not provide quantitative information for the FR, as it is only measuring the elemental bromine, chlorine, or phosphorus. Therefore, additional work is planned to compare the XRF with other FR screening and quantitative analytical techniques. These planned techniques include Handheld XRF [66] [72,73], Ion beam analysis/spectrometry (IBS/IBA) [51,52,74], High resolution 2D-gas chromatography-time-of-flight mass spectrometry(HRGCxGC-TOFMS) [75], and Thermal desorption-time-of-flight mass spectrometry (TD-HRGC-TOFMS) [54]. This additional work is expected to generate information which can be used to address issues related to ease-of-use, data comparability, and potential cost of analysis for some simpler analytical methods.

Finally, we believe that having readily available methods of identifying the class (or type) of polymers in the e-plastics is still an important need to address to allow for more recycling/reuse 
of e-plastics. While automatic sorting technologies are used in commercial plastics recycling, there is a need for techniques that may predict compression molding performance and, are lower cost and/or more portable. Future work therefore will include the evalution and use of polymer screening techniques such as infrared technologies (FT-IR, NDIR) or thermal analysis (differential scanning calorimetry (DSC), thermogravimetric analysis (TGA) etc.) to more thoroughly characterize the e-plastics mixtures tested for compression molding.

Supplementary Materials: The following are available online at www.mdpi.com/2078-1547/7/1/13/s1. Table S1: Full Data Set for Handheld XRF Analysis.

Acknowledgments: Funding for this work was provided in part through an internal Research and Artistry Grant to the authors by Northern Illinois University (NIU). Kevin Coleman (Olympus) is thanked for the XRF analysis assistance.

Author Contributions: William Mills and Robert A. Tatara both conceived, planned, conducted the experiments, reviewed and analyzed the data, and wrote the paper jointly.

Conflicts of Interest: The authors declare no conflict of interest.

\section{Abbreviations}

The following abbreviations are used in this manuscript:

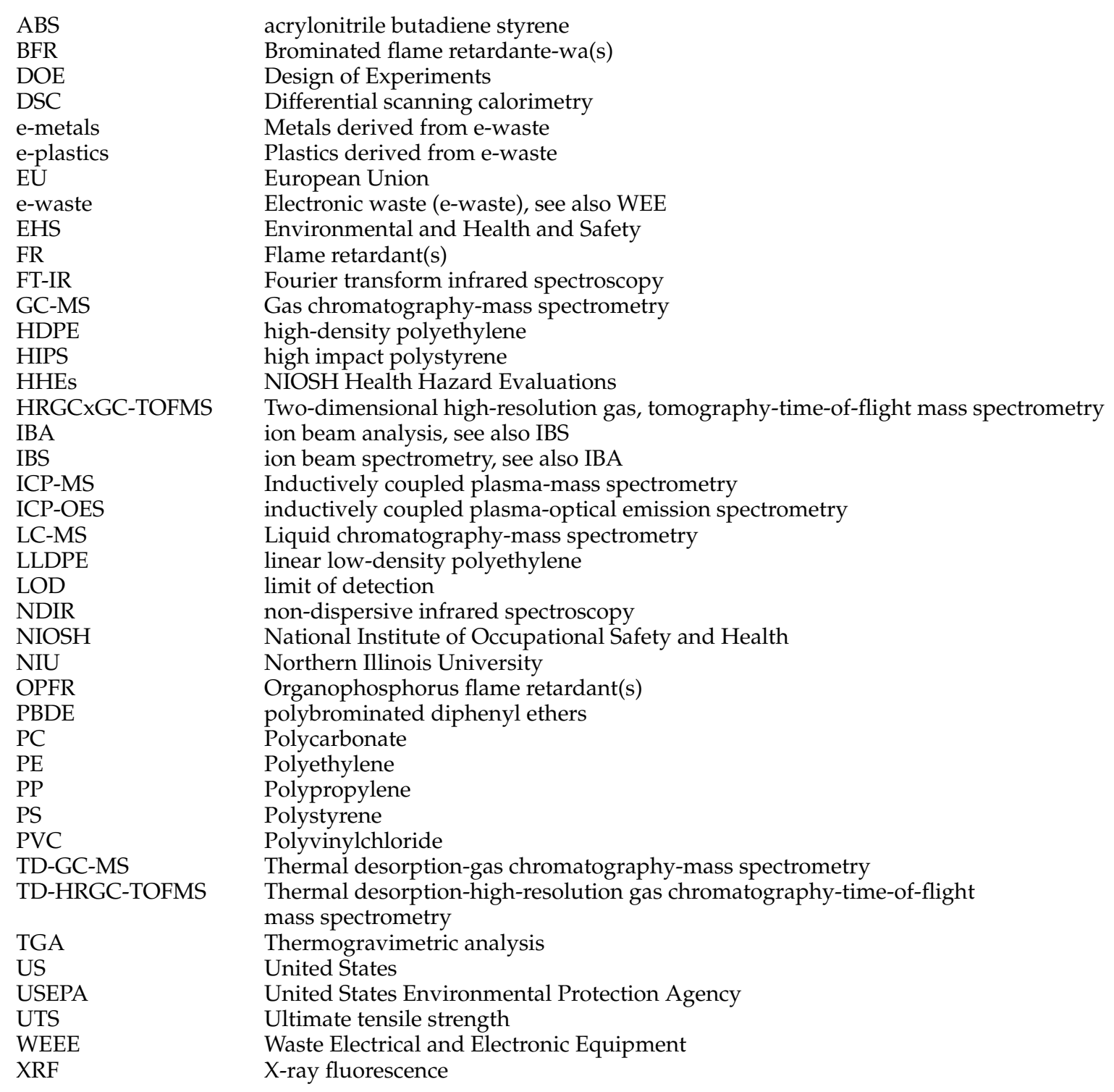




\section{References}

1. Kang, H.Y.; Schoenung, J.M. Electronic waste recycling: A review of US infrastructure and technology options. Resour. Conserv. Recycl. 2005, 45, 368-400. [CrossRef]

2. Cui, J.R.; Forssberg, E. Mechanical recycling of waste electric and electronic equipment: A review. J. Hazard. Mater. 2003, 99, 243-263. [CrossRef]

3. ElectronicsTakebackCoalition. Facts and Figures on E-Waste and Recycling. Available online: http:// www.electronicstakeback.com/wp-content/uploads/Facts_and_Figures_on_EWaste_and_Recycling.pdf (accessed on 19 October 2014).

4. Buekens, A.; Yang, J. Recycling of WEEE plastics: A review. J. Mater. Cycl. Waste Manag. 2014, 16, 415-434. [CrossRef]

5. United Nations University. 2008 Review of EU Directive on Waste Electrical and Electronic Equipment (WEEE) —Final Report. 2007. Available online: http://ec.europa.eu/environment/waste/weee/pdf/final_ rep_unu.pdf (accessed on 17 May 2016).

6. USEPA. Statistics on the Management of Used and End-of-Life Electronics. 2012. Available online: http: //www.epa.gov/osw/conserve/materials/ecycling/manage.htm (accessed on 19 October 2014).

7. ILEPA. Electronic Waste Recycling: Public Act 97-0287-Electronic Products Recycling \& Reuse Act. Available online: http://www.epa.state.il.us/land/electronic-waste-recycling/ (accessed on 19 October 2014).

8. Wang, R.X.; Xu, Z.M. Recycling of non-metallic fractions from waste electrical and electronic equipment (WEEE): A review. Waste Manag. 2014, 34, 1455-1469. [CrossRef] [PubMed]

9. Schut, J.H. Recycling E-Plastics New Material Stream Brings its Own Set of Problems. Available online: http:/ / www.ptonline.com/articles/recycling-e-plastics-new-material-stream-brings-its-own-setof-problems (accessed on 17 May 2016).

10. Hopewell, J.; Dvorak, R.; Kosior, E. Plastics recycling: Challenges and opportunities. Philosoph. Transac. Royal Soc. B Biol. Sci. 2009, 364, 2115-2126. [CrossRef] [PubMed]

11. Brown, M.T.; Buranakarn, V. Emergy indices and ratios for sustainable material cycles and recycle options. Resour. Conserv. Recycl. 2003, 38, 1-22. [CrossRef]

12. Schlummer, M.; Gruber, L.; Maurer, A.; Wolz, G.; van Eldik, R. Characterisation of polymer fractions from waste electrical and electronic equipment (WEEE) and implications for waste management. Chemosphere 2007, 67, 1866-1876. [CrossRef] [PubMed]

13. Wäger, P.; Boni, H.; Buser, A.; Morf, L.; Schluep, M.; Streicher, M. Recycling of Plastics from Waste Electrical and Electronic Equipment (WEEE)—Tentative Results of a Swiss Study. 2009. Available online: http: / / ewasteguide.info/files/Waeger_2009_R\%2709.pdf (accessed on 17 May 2016).

14. USEPA. High Speed Plastic Recycling. 2010. Available online: http://www.epa.gov/sites/production/files/ 2015-06/documents/nrt.pdf (accessed on 27 January 2016).

15. Faulkner, D.W. How well are we handling electronic-waste? In Proceedings of the 17th European Conference on Network and Optical Communications, Vilanova i la Geltru, Spain, 20-22 June 2012.

16. Deng, C.; Li, Y.; Li, J.H.; Li, H.F. A Mini-review on disposal of WEEE plastics containing PBDEs with a special focus on China. In Selected Proceedings of the Eighth International Conference on Waste Management and Technology; Li, J., Hu, H., Eds.; Trans Tech Publications Ltd.: Stafa-Zurich, Switzerland, 2014; pp. 600-608.

17. Yang, X.N.; Sun, L.S.; Xiang, J.; Hu, S.; Su, S. Pyrolysis and dehalogenation of plastics from waste electrical and electronic equipment (WEEE): A review. Waste Manag. 2013, 33, 462-473. [CrossRef] [PubMed]

18. Tue, N.M.; Takahashi, S.; Subramanian, A.; Sakai, S.; Tanabe, S. Environmental contamination and human exposure to dioxin-related compounds in e-waste recycling sites of developing countries. Environ. Sci. Proc. Impact. 2013, 15, 1326-1331. [CrossRef] [PubMed]

19. Shaw, S.D.; Berger, M.L.; Harris, J.H.; Yun, S.H.; Wu, Q.; Liao, C.; Blum, A.; Stefani, A.; Kannan, K. Persistent organic pollutants including polychlorinated and polybrominated dibenzo-p-dioxins and dibenzofurans in firefighters from northern California. Chemosphere 2013, 91, 1386-1394. [CrossRef] [PubMed]

20. Nnorom, I.C.; Osibanjo, O. Sound management of brominated flame retarded (BFR) plastics from electronic wastes: State of the art and options in Nigeria. Resour. Conserv. Recycl. 2008, 52, 1362-1372. [CrossRef]

21. Sthiannopkao, S.; Wong, M.H. Handling e-waste in developed and developing countries: Initiatives, practices, and consequences. Sci. Total Environ. 2013, 463, 1147-1153. [CrossRef] [PubMed] 
22. Dodder, N.G.; Strandberg, B.; Hites, R.A. Concentrations and spatial variations of polybrominated diphenyl ethers and several organochlorine compounds in fishes from the northeastern United States. Environ. Sci. Technol. 2002, 36, 146-151. [CrossRef] [PubMed]

23. Eguchi, A.; Isobe, T.; Ramu, T.; Tue, N.M.; Sudaryanto, A.; Davanathan, G.; Viet, P.H.; Tana, R.S.; Takahashi, S.; Subramanian, A.; et al. Soil contamination by brominated flame retardants in open waste dumping sites in Asian developing countries. Chemosphere 2013, 90, 2365-2371. [CrossRef] [PubMed]

24. Eguchi, A.; Nomiyama, K.; Devanathan, G.; Subramanian, A.; Bulbule, K.A.; Parthasarathy, P.; Takahashi, S.; Tanabe, S. Different profiles of anthropogenic and naturally produced organohalogen compounds in serum from residents living near a coastal area and e-waste recycling workers in India. Environ. Int. 2012, 47, 8-16. [CrossRef] [PubMed]

25. Ceballos, D.; Gong, W.; Page, E. Health Hazard Evaluation Report: A Pilot Assessment of Occupational Health Hazards in the U.S. Electronic Waste Recycling Industry. 2014. Available online: http:/ /www.cdc. gov/niosh/hhe/reports/pdfs/2012-0100-3217.pdf (accessed on 17 May 2016).

26. Ceballos, D.; Chen, L.; Page, E.; Echt, A.; Oza, A.; Ramsey, J. Health Hazard Evaluation Report: Evaluation of Occupational Exposures at an Electronic Scrap Recycling Facility. U.S. Department of Health and Human Services, Centers for Disease Control and Prevention, National Institute for Occupational Safety and Health: Cincinnati, OH, USA, 2014. Available online: http://www.cdc.gov/niosh/hhe/reports/pdfs/e-scrap_ survey_report.pdf (accessed on 17 May 2016).

27. Chen, A.M.; Yolton, K.; Rauch, S.A.; Webster, G.M.; Hornung, R.; Sjodin, A.; Dietrich, K.N.; Lanphear, B.P. Prenatal polybrominated diphenyl ether exposures and neurodevelopment in U.S. children through 5 years of age: The HOME study. Environ. Health Perspect. 2014, 122, 856-862. [CrossRef] [PubMed]

28. Sjodin, A.; Hagmar, L.; Klasson-Wehler, E.; Kronholm-Diab, K.; Jokobsson, E.; Bergman, A. Flame retardant exposure: Polybrominated diphenyl ethers in blood from Swedish workers. Environ. Health Perspect. 1999, 107, 643-648. [CrossRef] [PubMed]

29. Osibanjo, O.; Nnorom, I.C.; Ogbonna, K.C. Modelling waste generation by the telecom sector in Nigeria: The grey side of the impressive outing. Waste Manag. Res. 2008, 26, 317-326. [CrossRef] [PubMed]

30. Osibanjo, O.; Nnorom, I.C. Material flows of mobile phones and accessories in Nigeria: Environmental implications and sound end-of-life management options. Environ. Impact Assess. Rev. 2008, 28, $198-213$. [CrossRef]

31. Needhidasan, S.; Samuel, M.; Chidambaram, R. Electronic waste-An emerging threat to the environment of urban India. J. Environ. Health Sci. Eng. 2014, 12, 9. [CrossRef] [PubMed]

32. BFR 2014 Submitted Abstracts. 2014. Available online: http://www.bfr2014.indiana.edu/All\%20Abstracts. pdf (accessed on 19 October 2014).

33. Zhang, W.H.; Wu, Y.X.; Simonnot, M.O. Soil contamination due to e-waste disposal and recycling activities: A review with special focus on China. Pedosphere 2012, 22, 434-455. [CrossRef]

34. Ravi, V. Evaluating overall quality of recycling of e-waste from end-of-life computers. J. Clean. Produc. 2012, 20, 145-151. [CrossRef]

35. Wager, P.A.; Schluep, M.; Muller, E.; Gloor, R. RoHS regulated substances in mixed plastics from waste electrical and electronic equipment. Environ. Sci. Technol. 2012, 46, 628-635. [CrossRef] [PubMed]

36. Wäger, P.; Schluep, M.; Müller, E. RoHS Substances in Mixed Plastics from Waste Electrical and Electronic Equipment. 2010. Available online: http:/ / ewasteguide.info/files/Waeger_2010_Empa-WEEEForum.pdf (accessed on 17 May 2016).

37. Characterization and Failure Analysis of PLASTICS; Lampman, S., Ed.; ASM International: Novelty, OH, USA, 2003.

38. Portoles, T.; Sales, C.; Gomara, B.; Sancho, J.V.; Beltran, J.; Herrero, L.; Gonzalez, M.J.; Hernandez, F. Novel analytical approach for brominated flame retardants based on the use of gas chromatography-atmospheric pressure chemical ionization-tandem mass spectrometry with emphasis in highly brominated congeners. Anal. Chem. 2015, 87, 9892-9899. [CrossRef] [PubMed]

39. Samsonek, J.; Puype, F. Occurrence of brominated flame retardants in black thermo cups and selected kitchen utensils purchased on the European market. Food Add. Contam. A Chem. Anal. Control Exposure Risk Assess. 2013, 30, 1976-1986. [CrossRef] [PubMed]

40. van der Veen, I.; de Boer, J. Phosphorus flame retardants: Properties, production, environmental occurrence, toxicity and analysis. Chemosphere 2012, 88, 1119-1153. [CrossRef] [PubMed] 
41. Hall, W.J.; Williams, P.T. Analysis of products from the pyrolysis of plastics recovered from the commercial scale recycling of waste electrical and electronic equipment. J. Anal. Appl. Pyrol. 2007, 79, 375-386. [CrossRef]

42. Cajka, T.; Hajslova, J.; Kazda, R.; Poustka, J. Challenges of gas chromatography-high-resolution time-of-flight mass spectrometry for simultaneous analysis of polybrominated diphenyl ethers and other halogenated persistent organic pollutants in environmental samples. J. Sep. Sci. 2005, 28, 601-611. [CrossRef] [PubMed]

43. Kopp, E.K.; Fromme, H.; Volkel, W. Analysis of common and emerging brominated flame retardants in house dust using ultrasonic assisted solvent extraction and on-line sample preparation via column switching with liquid chromatography-mass spectrometry. J. Chromatogr. A 2012, 1241, 28-36. [CrossRef] [PubMed]

44. Zhou, S.N.; Reiner, E.J.; Marvin, C.; Helm, P.; Riddell, N.; Dorman, F.; Misselwitz, M.; Shen, L.; Crozier, P.; Macpherson, K.; et al. Development of liquid chromatography atmospheric pressure chemical ionization tandem mass spectrometry for analysis of halogenated flame retardants in wastewater. Anal. Bioanal. Chem. 2010, 396, 1311-1320. [CrossRef] [PubMed]

45. Vilaplana, F.; Karlsson, P.; Ribers-Greus, A.; Ivarsson, P.; Karlsson, S. Analysis of brominated flame retardants in styrenic polymers-Comparison of the extraction efficiency of ultrasonication, microwave-assisted extraction and pressurised liquid extraction. J. Chromatogr. A 2008, 1196, 139-146. [CrossRef] [PubMed]

46. Debrauwer, L.; Riu, A.; Jouahri, M.; Rathahao, E.; Jouanin, I.; Antignac, J.P.; Cariou, R.; Le Bize, B.; Zalko, D. Probing new approaches using atmospheric pressure photo ionization for the analysis of brominated flame retardants and their related degradation products by liquid chromatography-mass spectrometry. J. Chromatogr. A 2005, 1082, 98-109. [CrossRef] [PubMed]

47. Cui, J.; Forssberg, E. Characterization of shredded television scrap and implications for materials recovery. Waste Manag. 2007, 27, 415-424. [CrossRef] [PubMed]

48. Aldrian, A.; Ledersteger, A.; Pomberger, R. Monitoring of WEEE plastics in regards to brominated flame retardants using handheld XRF. Waste Manag. 2015, 36, 297-304. [CrossRef] [PubMed]

49. Gallen, C.; Banks, A.; Brandsma, S.; Baduel, C.; Thai, P.; Eaglesham, G.; Heffernan, A.; Leonards, P.; Bainton, P.; Mueller, J.F. Towards development of a rapid and effective non-destructive testing strategy to identify brominated flame retardants in the plastics of consumer products. Sci. Total Environ. 2014, 491, 255-265. [CrossRef] [PubMed]

50. Taurino, R.; Cannio, M.; Mafredini, T.; Pozzi, P. An efficient and fast analytical procedure for the bromine determination in waste electrical and electronic equipment plastics. Environ. Technol. 2014, 35, 3147-3152. [CrossRef] [PubMed]

51. Peaslee, G.F. Methods for Identification of Flame Retardants in Polyurethane Foam. Available online: http:/ / www.pfa.org/abstracts/abmay13.html (accessed on 17 May 2016).

52. Peaslee, G.F.; DeYoung, P.A. An Undergraduate Ion Beam Analysis Laboratory in International Topical Meeting on Nuclear Research Applications and Utilization of Accelerators. 2009. Available online: http: //www-pub.iaea.org/MTCD/publications/PDF/P1433_CD/datasets/papers/sm_ae-02.pdf (accessed on 17 May 2016).

53. Lazarov, B.; Swinnen, R.; Spruyt, M.; Maes, F.; Van Campenhout, K.; Goelen, E.; Covaci, A.; Strager, M. Air sampling of flame retardants based on the use of mixed-bed sorption tubes-a validation study. Environ. Sci. Pollut. Res. 2015, 22, 18221-18229. [CrossRef] [PubMed]

54. JEOL. Analysis of Additives in Plastic by Thermal Desorption (TD) GC-TOFMS-Accurate Mass Measurement and Isotope Pattern Matching. MS-Tips 2009. Available online: http://www.jeol.co.jp/ en/applications/pdf/ms/mstips138e.pdf (accessed on 19 October 2014).

55. Hosaka, A.; Watanabe, C.; Tsuge, S. Rapid determination of decabromodiphenyl ether in polystyrene by thermal desorption-GC/MS. Anal. Sci. 2005, 21, 1145-1147. [CrossRef] [PubMed]

56. Tatara, R. Compression molding. In Applied Plalstics Engineering Handbook; Kutz, M., Ed.; Elsevier: New York, NY, USA, 2011.

57. Athalya, A.S. Plastic Materials Handbook; Multi Tech Publishing Co.: Bombay, India, 1991.

58. Sinha, S.; Kumar, V. Polymer Systems and Applications; Stadium Press (India) Pvt. Ltd.: New Delhi, India, 2010.

59. OTA. Chapter 7 Case Study: Polymer Matrix Composites in Automobiles, in Advanced Materials by Design; Office of Technology Assessment: Washington, DC, USA, 1988.

60. Malnat, P. Inside Manufacturing: A Reinforced Thermoplastic Car Hood? Available online: http://www. compositesworld.com/articles/inside-manufacturing-a-reinforced-thermoplastic-car-hood (accessed on 17 May 2016). 
61. Lakshmi, R.; Nagan, S. Utilization of waste E plastic particles in cementitious mixtures. J. Struct. Eng. 2011, 38, 26-35.

62. Arnold, J.C.; Alston, S.; Holder, A. Void formation due to gas evolution during the recycling of Acrylonitrile-Butadiene-Styrene copolymer (ABS) from waste electrical and electronic equipment (WEEE). Polymer Degrad. Stab. 2009, 94, 693-700. [CrossRef]

63. Balart, R.; Lopez, J.; Garcia, D.; Salvador, M.D. Recycling of ABS and PC from electrical and electronic waste. Effect of miscibility and previous degradation on final performance of industrial blends. Eur. Polymer J. 2005, 41, 2150-2160. [CrossRef]

64. Mahanta, D.; Dayanidhi, S.A.; Mohanty, S.; Nayak, S.K. Mechanical, thermal, and morphological properties of recycled polycarbonate/recycled poly(acrylonitrile-butadiene-styrene) blend nanocomposites. Polymer Comp . 2012, 33, 2114-2124. [CrossRef]

65. Strong, A.B. Plastics: Materials and Processing; Pearson Education, Inc.: Upper Saddle River, NJ, USA, 2006.

66. Mills, W.; Tracy, A.; Cline-Thomas, A. Integrated application of field screening: A case study. In Proceedings of 3rd International Symposium on Field Screening Methods for Hazardous Wastes and Toxic Chemicals, Las Vegas, NV, USA, 1993.

67. Carver Bench Top Standard Auto Series Model Presses. Available online: http://www.carverpress.com/ benchtop_auto_standard.html (accessed on 24 April 2016).

68. ASTM. Standard Test Method for Tensile Properties of Plastics. 2014. Available online: http:/ /www.astm. org/Standards/D638.htm (accessed on 17 May 2016).

69. Lloyd Instruments EZ Series EZ50 $50 \mathrm{kN}$ Universal Materials Testing Machine. 2007. Available online: http:/ / www.jlwinstruments.com/index.php/products/products-library/ez50-50-kn-universalmaterials-testing-machine-ez-series / (accessed on 17 May 2016).

70. Olympus. Delta Professional XRF Analyzers. Available online: http://www.olympus-ims.com/vi/xrf-xrd/ delta-handheld/delta-prof/ (accessed on 21 February 2016).

71. Coleman, K.; Olympus USA, Center Valley, PA, USA; Mills, W.; INorthern Illinois University, DeKalb, IL, USA. Personal communication, 2015.

72. EU. Restriction of Hazardous Substances in Electrical and Electronic Equipment. 2002. Available online: http:/ / ec.europa.eu/environment/waste/rohs_eee/legis_en.htm (accessed on 17 May 2016).

73. ThermoFisher. Handheld XRF. 2014. Available online: http://www.thermoscientific.com/content/tfs/en/ products/handheld-xrf.html (accessed on 19 October 2014).

74. Maley, A.M.; Falk, K.A.; Hoover, L.; Earlywine, E.B.; Seymour, M.D.; DeYoung, P.A.; Blum, A.; Stapleton, H.M.; Peaslee, G.F. Detection of halogenated flame retardants in polyurethane foam by particle induced X-ray emission. Nuclear Instr. Method. Phys. Res. B Beam Interact. Mater. Atom. 2015, 358, $21-25$. [CrossRef]

75. SGS. Ultratrace. 2014. Available online: http://www.sgsgroup.us.com/en/Environment/Soil/LaboratoryAnalysis/Specialty-Analyses/Ultratrace.aspx (accessed on 19 October 2014).

(C) 2016 by the authors; licensee MDPI, Basel, Switzerland. This article is an open access article distributed under the terms and conditions of the Creative Commons Attribution (CC-BY) license (http://creativecommons.org/licenses/by/4.0/). 